\title{
Cl gene cluster encoding several small nucleolar RNAs: a comparison amongst trypanosomatids
}

\author{
Paola Nocua, Carolina Gómez, Claudia Cuervo, Concepción Puerta/ ${ }^{+}$ \\ Laboratorio de Parasitología Molecular, Departamento de Microbiología, Facultad de Ciencias, Pontificia Universidad Javeriana, \\ Carrera 7 43-82, Lab. 113, Bogotá, Colombia
}

\begin{abstract}
Small nucleolar RNAs (snoRNAs) are small non-coding RNAs that modify RNA molecules such as rRNA and SnRNA by guiding 2'-O-ribose methylation (C/D box snoRNA family) and pseudouridylation reactions (H/ACA snoRNA family). H/ACA snoRNAs are also involved in trans-splicing in trypanosomatids. The aims of this work were to characterise the $\mathrm{Cl}$ gene cluster that encodes several snoRNAs in Trypanosoma rangeli and compare it with clusters from Trypanosoma cruzi, Trypanosoma brucei, Leishmania major, Leishmania infantum, Leishmania braziliensis and Leptomonas collosoma. The T. rangeli $\mathrm{Cl}$ gene cluster is an 801 base pair (bp) repeat sequence that encodes three C/D (Cll, Cl2 and Cl4) and three H/ACA (Cl3, Cl5 and Cl6) snoRNAs. In contrast to T. brucei, the Cl3 and Cl5 homologues have not been annotated in the Leishmania or T. cruzi genome projects (http//:www.genedb. org). Of note, snoRNA transcribed regions have a high degree of sequence identity among all species and share gene synteny. Collectively, these findings suggest that the Cl cluster could constitute an interesting target for therapeutic (gene silencing) or diagnostic intervention strategies (PCR-derived tools).
\end{abstract}

Key words: C/D snoRNA - H/ACA snoRNA - rRNA - Trypanosoma rangeli - trypanosomatid

Small nucleolar RNAs (snoRNAs) are a defined population of non-protein coding RNAs that guide posttranscriptional modifications of ribosomal RNA (rRNA) and some spliceosomal small nuclear RNAs (snRNAs) that are crucial for appropriate RNA folding, as well as RNA-RNA and RNA-protein interactions (Weinstein \& Steitz 1999). These 60-300 nucleotide (nt)-long RNAs exist as snoRNA-protein complexes called snoRNPs. Most snoRNAs can be divided into two classes on the basis of their function and the presence of conserved sequence motifs; one contains two such motifs, box C (5' -RUGAUGA-3') and box D (5' -CUGA-3') along with two more degenerate internal copies of these elements, C' and D' boxes (Kiss-Laszlo et al. 1998); the other group contains the H (ANANNA) and ACA motifs (Maxwell $\&$ Fournier 1995). A few snoRNAs in each family are involved in pre-rRNA processing, but most are associated with nucleotide modification. Box C/D snoRNAs guide 2'-O-ribose methylation (Samarsky et al. 1998), while H/ ACA snoRNAs guide pseudouridine formation (Balakin et al. 1996). The snoRNAs interact directly with their RNA targets through base complementarity and methylation or uridine isomerisation reactions are catalysed by core snoRNP proteins. Each box C/D snoRNP contains a single snoRNA harbouring the $\mathrm{C}$ and $\mathrm{D}$ elements required for snoRNA nucleolar localization, accumulation, maturation and protein association (Samarsky et

Financial support: Vicerrectoría Académica, PUJ (1707)

+Corresponding author: cpuerta@javeriana.edu.co

P Nocua and C Gómez contributed equally to this work.

Received 8 October 2008

Accepted 3 March 2009 al. 1998). Box C/D snoRNAs have one or two regions of sequence complementarity to specific region(s) in the rRNA (Bachellerie et al. 1995).

These 10-20 nt guide sequences reside immediately upstream of box D or D' and form duplexes with the target RNA, directing methylation of the fifth nucleotide $(+5)$ that is paired upstream of the 5' end of box D or D'; this is known as the " +5 rule" (Decatur \& Fournier 2003). The C/D snoRNAs of trypanosomatids such as Leptomonas collosoma (Levitan et al. 1998, Xu et al. 2001, Liang et al. 2004, Uliel et al. 2004), Trypanosoma brucei (Roberts et al. 1998, Dunbar et al. 2000a, b, Liang et al. 2005), Leishmania tarentolae (Roberts et al. 1998), Leishmania major (Uliel et al. 2004, Liang et al. 2007), Trypanosoma cruzi (Roberts et al. 1998, Uliel et al. 2004) and Trypanosoma rangeli (Morales et al. 2002) exhibit the same general structure and follow the +5 rule as well. Some trypanosomatid C/D snoRNAs are also able to guide methylation at two different sites in the same rRNA molecule or even in two different rRNAs, acting as double guides (Morales et al. 2002).

Box H/ACA snoRNAs have two conserved elements: the $\mathrm{H}$ domain (located in a hinge region joining two functionally similar hairpin domains) and the ACA triplet located 3 nt upstream from the 3' end. Two short rRNA recognition motifs within the snoRNA pair with rRNA sequences flanking the target uridine, which is always 1416 nt upstream of the snoRNA H or ACA box (Ganot et al. 1997). The two internal loops within the H/ACA snoRNA usually contain complementary rRNA domains ( $\mathrm{Ni}$ et al. 1997). These snoRNAs form a single hairpin in trypanosomatids ending in the AGA triplet instead of ACA (Liang et al. 2001, 2002, 2004, 2007, Barth et al. 2005).

Arranged differently from mammalians, most of trypanosomatid snoRNAs are clustered in tandem repeats and carry a mix of both snoRNA families (Dunbar et 
al. 2000a, Morales et al. 2002, Liang et al. 2007). This genomic organisation resembles that of plants in which snoRNAs are also clustered and transcribed as polycistronic snoRNA precursors (Brown et al. 2003).

T. rangeli is a hemoflagellate protozoan parasite that, in contrast to T. cruzi (the etiologic agent of Chagas disease), is considered to be non-pathogenic to mammalian hosts (D'Alessandro \& Saravia 1999). Despite its lack of human pathogenicity, T. rangeli is a serious concern for human Chagas disease epidemiology and diagnosis (Guhl \& Vallejo 2003). Recent studies have classified $T$. rangeli into $\mathrm{KP} 1(+)$ and $\mathrm{KP} 1(-)$ strains, which are related to transmission-vector ability (Vallejo et al. 2003, 2007).

The $\mathrm{Cl}$ gene cluster (coding for several snoRNAs) was characterised in this work in a representative strain from each $T$. rangeli group and compared to those from T. cruzi, T. brucei, L. major, Leishmania infantum, Leishmania braziliensis and L. collosoma.

\section{MATERIALS AND METHODS}

Parasites - Epimastigotes from the T. rangeli KP1(+) H14 strain (MHOM/Hond/H14) (Acosta et al. 1991) were used in this study. They were characterised by using S35/S36/KP1L PCR (Vallejo et al. 2002). Parasites were grown at $26^{\circ} \mathrm{C}$ in modified LIT medium supplemented with $15 \%(\mathrm{v} / \mathrm{v})$ heat-inactivated foetal bovine serum.

PCR amplification, cloning and nucleotide sequence PCR was performed using TrF1 (5' - CGC CCC GTC TTG CCC TGT-3') and TrR2 (5' - CGC AGC AAG GAC AGG AGG GA-3') primers, which, based on the T. rangeli KP1() C23 (MAOT/CO/82/C23) (Zuñiga et al. 1997) strain, amplify a $620 \mathrm{bp}$ fragment exclusively in $T$. rangeli. A $25 \mu \mathrm{L}$ reaction contained $100 \mathrm{ng}$ purified genomic DNA, $1 \mathrm{X}$ reaction buffer $(10 \mathrm{mM}$ Tris- $\mathrm{HCl} \mathrm{pH} 9.0,50 \mathrm{mM} \mathrm{KCl}$ and $0.1 \%$ Triton X-100), 1.25 units of Expand High Fidelity enzyme (Roche, Branford, USA), $1.5 \mathrm{mM} \mathrm{MgCl}, 0.2$ $\mathrm{mM}$ of each deoxynucleoside triphosphate and $20 \mathrm{pmol}$ of each primer. Reactions were carried out in an MJ Research PTC-100 DNA thermal cycler using the following method: $94^{\circ} \mathrm{C} / 5 \mathrm{~min}, 15$ cycles of $95^{\circ} \mathrm{C} / 30 \mathrm{~s}, 63^{\circ} \mathrm{C} / 1 \mathrm{~min}$, $72^{\circ} \mathrm{C} / 30 \mathrm{~s}$ and 20 cycles of $95^{\circ} \mathrm{C} / 30 \mathrm{~s}, 60^{\circ} \mathrm{C} / 1 \mathrm{~min}, 72^{\circ} \mathrm{C} / 30$ $\mathrm{s}$ and a final incubation of $72^{\circ} \mathrm{C}$ for $5 \mathrm{~min}$. Amplified fragments were purified from an agarose gel using a GFX Gel Band Purification kit (Amersham Biosciences) and cloned into the pGEM-T Easy plasmid (Promega). Both cloned fragment strands were sequenced by the Sanger method (Sanger et al. 1977) in a 373 Automatic DNA sequencer (Pharmacia LKB) using universal and specific primers.

Sequence analysis - Sequence of an $801 \mathrm{bp}$ fragment from the $T$. rangeli $\mathrm{KP} 1(-) \mathrm{C} 23$ strain was retrieved from GenBank (accession AY028385) and included for comparative analyses. The $T$. rangeli $\mathrm{KP} 1++) \mathrm{H} 14$ strain sequence produced in this study is available from the GenBank database (accession EF100612). Homology searches were performed in GenBank and parasite genome project databases (http://www.genedb.org) using the BLAST program (Stephen et al. 1997); pair-wise and multiple sequence alignments were carried out using LALIGN (Pearson 1990) and ClustalW (Thompson et al. 1994) software, respectively.

\section{RESULTS}

Analysing the $\mathrm{Cl}$ gene cluster from $\mathrm{T}$. rangeli BLASTN comparative analysis of the previously reported $801 \mathrm{bp}$ fragment coding for snoRNA-Cll of the T. rangeli $\mathrm{C} 23$ strain (Morales et al. 2002) and T. brucei GeneDB version 4.0 revealed the presence of additional genes coding for five snoRNAs. This gene cluster repeat (named $\mathrm{Cl}$ ) encoded six snoRNAs, three $\mathrm{C} / \mathrm{D}(\mathrm{Cl1}, \mathrm{Cl} 2$ and $\mathrm{Cl} 4)$ and three $\mathrm{H} / \mathrm{ACA}(\mathrm{Cl} 3, \mathrm{Cl} 5$ and $\mathrm{Cl} 6)$, organised from the 5' end from $\mathrm{Cl} 2, \mathrm{Cl} 3, \mathrm{Cl} 4, \mathrm{Cl}$, $\mathrm{Cl} 6$ to $\mathrm{Cl}$. All C/D snoRNAs exhibited the consensus C, D, C' and D' boxes and regions having sequence complementarity to the methylation site on rRNA (Fig.1). Like other trypanosomatids, $\mathrm{Cl}$ gene cluster H/ACA snoRNAs formed

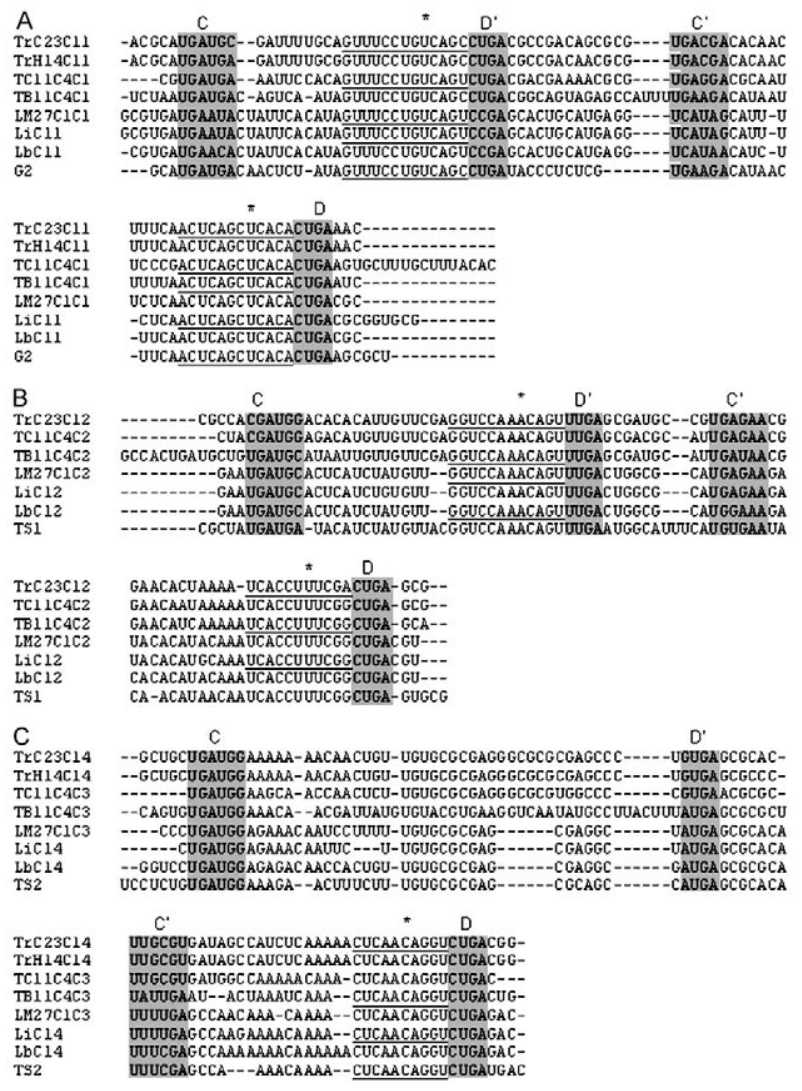

Fig. 1: CLUSTAL W multiple sequence alignment of C/D Cl-small nucleolar RNAs (snoRNAs) from different trypanosomatid species. A: snoRNA C11; B: snoRNA Cl2; C: snoRNA Cl4. The C, C', D and D' boxes are shaded, the rRNA complementarity regions are underlined and the gaps are shown as short lines. Asterisk denotes the methylation site. The species designations are as follows: TrC23: Trypanosoma rangeli $\mathrm{C} 23$ (GenBanK accession AY028385); TrH14: T. rangeli $\mathrm{H} 14$ (GenBanK accession EF100612); TC11: Trypanosoma cruzi (GeneDB contig 4406, Tc00.1047053487475.10, Tc00.1047053487475.20 and Tc00.1047053487475.30),TB11:T.brucei(GeneDBTb11_snoRNA_0005, Tb11_snoRNA_0004 and Tb11_snoRNA_0002); LM27: Leishmania major (GeneDB LmjF27.snoRNA.0004, LmjF27.snoRNA.0001 and LmjF27.snoRNA.0002); Li: Leishmania infantum (Chromosome 27, accession AM502245) and Lb: Leishmania brazilensis (Chromosome 27, GenBank accession AM494964). G2, TS1 and TS2 sequences are from Leptomonas collosoma (GenBank accession AF331656). 
A

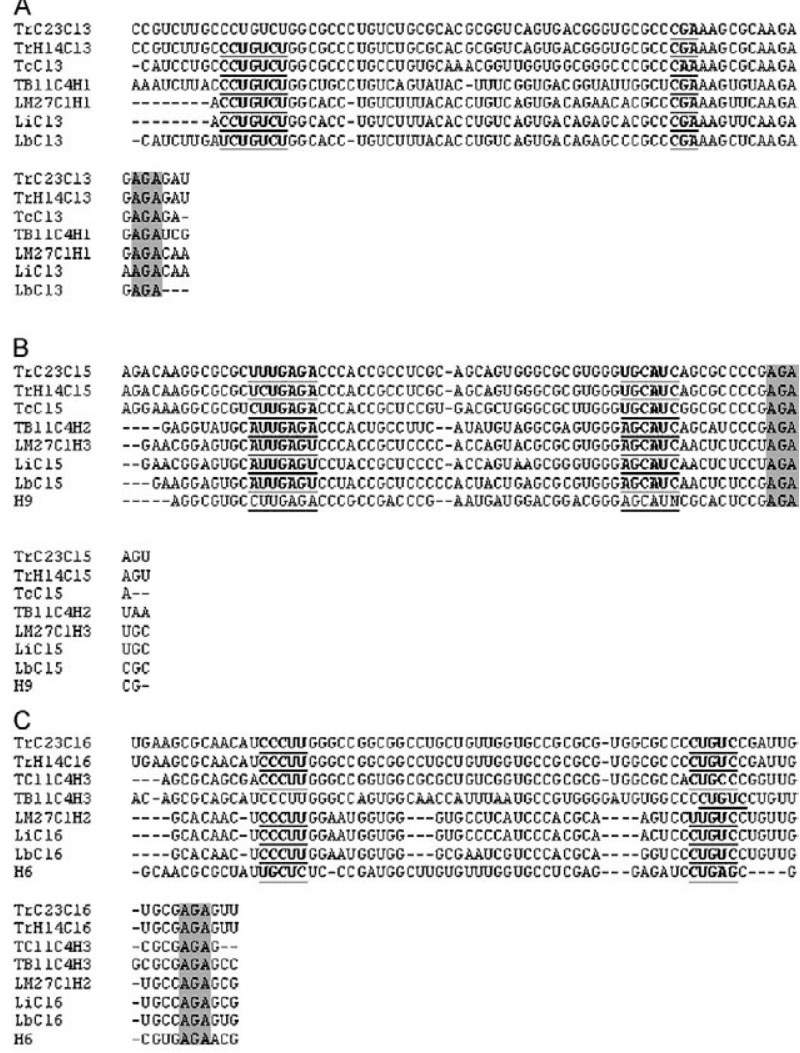

Fig. 2: multiple sequence alignment by CLUSTAL W of H/ACA Clsmall nucleolar RNAs (snoRNAs) from different trypanosomatid species. A: snoRNA Cl3; B: snoRNA Cl5; C: sno RNA Cl6. The AGA boxes are shaded, the rRNA complementarity regions are underlined and the gaps are shown as short lines. The species designation are as follows: TrC23: Trypanosoma rangeli $\mathrm{C} 23$ (GenBank accession AY028385); TrH14 T. rangeli H14 (GenBank accession EF100612); TC11: Trypanosoma cruzi (GeneDB contig 4406, Tc00.1047053487475.40); TB11: Trypanosoma brucei (GeneDB Tb11_snoRNA_0003, Tb11_ snoRNA_0001 and Tb11_snoRNA_0006); LM27: Leishmania major (GeneDB LmjF27.snoRNA.0012, LmjF27.snoRNA.0003 and LmjF27. snoRNA.0011); Li: Leishmania infantum (Chromosome 27, accession AM502245); Lb: Leishmania brazilensis (Chromosome 27, GenBank accession AM494964). H6 and H9 sequences are from Leptomonas collosoma (Liang et al. 2004).

single hairpins ending in the AGA motif (Fig.2). Amplified sequence from the $\mathrm{Cl}$ gene cluster in the T. rangeli H14 strain (corresponding to nts 163-782 of the C23 strain) revealed $96.5 \%$ identity between the sequences of both strain, exhibiting two transversions, five transitions and two insertion-deletions (Table I).

Comparing the $T$. rangeli $\mathrm{Cl}$ gene cluster sequence with its homologue in T. cruzi - Comparative analysis of the $T$. rangeli $\mathrm{C} 23$ sequence with the $T$. cruzi genome revealed $81-88 \%$ identity between $\mathrm{Cl} 1$ and $\mathrm{TC} 11 \mathrm{C} 4 \mathrm{C} 1$, $\mathrm{Cl} 2$ and $\mathrm{TC} 11 \mathrm{C} 4 \mathrm{C} 2, \mathrm{Cl} 4$ and $\mathrm{TC} 11 \mathrm{C} 4 \mathrm{C} 3$ and $\mathrm{Cl} 6$ and TC11C4H3 (Table II). Since the current $T$. cruzi genome assembly and annotation version is fragmented and redundant, all contigs containing the $\mathrm{Cl}$ gene cluster were aligned with $T$. rangeli sequences. The analysis revealed
TABLE I

Comparison of $\mathrm{Cl}$ gene cluster sequences between $\mathrm{KP} 1(+)$ $\mathrm{H} 14$ and KP1(-) C23 strains of Trypanosoma rangeli

\begin{tabular}{|c|c|c|c|c|c|}
\hline \multirow[b]{2}{*}{ Mutation } & \multirow{2}{*}{$\begin{array}{l}\text { Position } \\
\text { H14/C23 }\end{array}$} & \multirow{2}{*}{$\begin{array}{l}\text { Change } \\
\mathrm{H} 14 / \mathrm{C} 23\end{array}$} & \multicolumn{2}{|c|}{$\begin{array}{l}\text { Affected } \\
\text { region }\end{array}$} & \multirow[b]{2}{*}{ snoRNA } \\
\hline & & & TR & NTR & \\
\hline Transversion & $176 / 338$ & $\mathrm{C} / \mathrm{A}$ & $\mathrm{x}$ & & $\mathrm{Cl} 4$ \\
\hline Insertion/deletion & $236 / 398$ & $\mathbf{\Delta} / \mathrm{C}$ & & $\mathrm{x}$ & $\mathrm{C} 14-\mathrm{Cl} 5$ \\
\hline Transition & $261 / 424$ & $\mathrm{C} / \mathrm{T}$ & $\mathrm{x}$ & & $\mathrm{Cl} 5$ \\
\hline Transition & $474 / 637$ & $\mathrm{C} / \mathrm{T}$ & & $\mathrm{x}$ & Cl6-Cl1 \\
\hline Transversion & $488 / 651$ & $\mathrm{~A} / \mathrm{C}$ & $\mathrm{x}$ & & Cl1 \\
\hline Transition & $497 / 660$ & $\mathrm{G} / \mathrm{A}$ & $\mathrm{x}$ & & $\mathrm{Cl1}$ \\
\hline Transition & $523 / 686$ & $\mathrm{~A} / \mathrm{G}$ & $\mathrm{x}$ & & $\mathrm{Cl1}$ \\
\hline Transition & $604 / 753$ & $\mathrm{C} / \mathrm{T}$ & & $\mathrm{x}$ & C11-3' en \\
\hline Insertion- deletion & $581 / 743$ & $\triangle / \mathbf{\Delta}$ & & $\mathrm{x}$ & Cl1-3' en \\
\hline
\end{tabular}

NTR: non-transcribed region; snoRNAs: small nucleolar RNAs; TR: transcribed region; $\mathbf{\Delta}$ : deletion; $\triangle$ : sequence CCCCCCCTCTTTTT.

the presence of $\mathrm{Cl} 3$ and $\mathrm{Cl} 5$ homologues in $T$. cruzi (84.9\% and $81.2 \%$ identity, respectively).

It was also found that the gene order within the $\mathrm{Cl}$ cluster was conserved in both trypanosomes. In fact, transcribed regions were highly conserved between both species whereas non-transcribed regions differed in both size and sequence (Table III). The genomic sequence contained 103 contigs that include Cl-snoRNAs (T. cruzi GeneDB, version 4.0). Some of them, like contig 7066, carried other genes such as those coding for phosphatidylinositol kinase (Tc00.1047053506719.10), which corresponds to orthologues Tb11.47.0002 and LmjF27.0890 in T. brucei and L. major, respectively.

Comparing the $\mathrm{T}$. rangeli $\mathrm{Cl}$ gene cluster sequence with its homologue in other trypanosomatids - Homologues for all $\mathrm{Cl}$ genes were detected in T. brucei, L. major, L. infantum and L. braziliensis, having $61.6-85.4 \%$ identity with T. brucei and 58.4-79.2\% with the Leishmania species (Table II). All Cl-snoRNAs of L. collosoma were found to share $62.5-78.8 \%$ identity with those $T$. rangeli, except for $\mathrm{Cl} 3$ (Table II). Multiple alignments of all trypanosomatid snoRNAs revealed conservation of both sequence and position for the characteristic motifs of each snoRNA family (Figs 1, 2). Table IV shows the rRNA modifications carried out by Cl-snoRNA homologues from trypanosomatids, yeasts, plants and humans. $\mathrm{Cl}$ gene cluster organisation and genome location was studied in the trypanosomatid genome projects. This cluster in T. brucei was repeated five times, consisting of 32 snoRNA genes that maintained the same $T$. rangeli snoRNA gene order and were located on the antisense strand of chromosome 11 in position 456973-461605 ( $T$. brucei GeneDB, version 4.0).

This cluster was flanked upstream by a gene encoding the isovaleryl-CoA dehydrogenase protein (Tb11.55.0026) and downstream by two ESAG genes (Tb11.55.0027 and Tb11.55.0028). It is worth noting that a phosphatidylinosi- 
TABLE II

Comparison of Cl-small nucleolar RNAs (snoRNAs) from Trypanosoma rangeli $\mathrm{C} 23 \mathrm{KP} 1(-)$ strain with their homologue sequences in different trypanosomatids

\begin{tabular}{|c|c|c|c|c|}
\hline \multirow[b]{2}{*}{$\begin{array}{l}\text { T. rangeli } \\
\text { snoRNAs }\end{array}$} & \multicolumn{4}{|c|}{ Trypanosomatid homologue snoRNAs } \\
\hline & Name & Specie & $\begin{array}{c}\text { Length } \\
\text { nt }\end{array}$ & $\begin{array}{c}\text { Identity } \\
\%\end{array}$ \\
\hline \multirow{6}{*}{$\begin{array}{l}\mathrm{Cl} 2 \\
(88 \mathrm{nt})\end{array}$} & $\mathrm{TC} 11 \mathrm{Cs} 4 \mathrm{C} 2$ & T. cruzi & 87 & 88.8 \\
\hline & TB11Cs4C2 & T. brucei & 97 & 85.4 \\
\hline & LM27Cs1C2 & L. major & 84 & 72.3 \\
\hline & $\mathrm{LiCl} 2$ & L. infantum & 84 & 72.3 \\
\hline & $\mathrm{LbCl} 2$ & L. braziliensis & 84 & 68.3 \\
\hline & TS1 & L. collosoma & 84 & 78.8 \\
\hline \multirow{6}{*}{$\begin{array}{l}\mathrm{Cl3} \\
\text { (75 nt) }\end{array}$} & $\mathrm{TrH} 14 \mathrm{Cl} 3$ & T. rangeli $\mathrm{H} 14$ & 75 & 100 \\
\hline & $\mathrm{TcCl} 3$ & T. cruzi & 73 & 84.9 \\
\hline & TB11Cs4H1 & T. brucei & 73 & 72.9 \\
\hline & LM27Cs1H1 & L. major & 66 & 77.3 \\
\hline & $\mathrm{LiCl} 3$ & L. infantum & 66 & 77.3 \\
\hline & $\mathrm{LbCl} 3$ & L. braziliensis & 70 & 79.2 \\
\hline \multirow{7}{*}{$\begin{array}{l}\text { Cl4 } \\
\text { (99 nt) }\end{array}$} & $\operatorname{TrC} 23 \mathrm{Cl} 14$ & T. rangeli $\mathrm{H} 14$ & 99 & 99 \\
\hline & TC11Cs4C3 & T. cruzi & 90 & 83.8 \\
\hline & TB11Cs4C3 & T. brucei & 101 & 61.6 \\
\hline & LM27Cs1C3 & L. major & 87 & 71.3 \\
\hline & $\mathrm{LiCl} 4$ & L. infantum & 85 & 71.3 \\
\hline & $\mathrm{LbCl} 4$ & L. braziliensis & 91 & 72.2 \\
\hline & TS2 & L. collosoma & 90 & 72.3 \\
\hline \multirow{7}{*}{$\begin{array}{l}\mathrm{Cl5} \\
\text { (71 nt) }\end{array}$} & $\operatorname{TrH} 14 \mathrm{Cl} 5$ & T. rangeli $\mathrm{H} 14$ & 71 & 98.6 \\
\hline & $\mathrm{TcCl} 5$ & T. cruzi & 69 & 81.2 \\
\hline & TB11Cs4H2 & T. brucei & 66 & 76.2 \\
\hline & LM27Cs1H3 & L. major & 69 & 74.2 \\
\hline & $\mathrm{LiCl5}$ & L. infantum & 69 & 71.2 \\
\hline & $\mathrm{LbCl} 5$ & L. braziliensis & 69 & 74.6 \\
\hline & H9 & L. collosoma & 64 & 73.8 \\
\hline \multirow{7}{*}{$\begin{array}{l}\mathrm{Cl6} \\
\text { (77 nt) }\end{array}$} & TrH14Cl6 & T. rangeli $\mathrm{H} 14$ & 77 & 100 \\
\hline & TC11Cs4H3 & T. cruzi & 72 & 85.7 \\
\hline & TB11Cs4H3 & T. brucei & 78 & 74.3 \\
\hline & LM27Cs1H2 & L. major & 66 & 64.8 \\
\hline & LiCl6 & L. infantum & 66 & 58.4 \\
\hline & $\mathrm{LbCl} 6$ & L. brazilensis & 66 & 66.7 \\
\hline & H6 & L. collosoma & 70 & 62.5 \\
\hline \multirow{7}{*}{$\begin{array}{l}\text { Cl1 } \\
\text { (86 nt) }\end{array}$} & TrH14Cl1 & T. rangeli $\mathrm{H} 14$ & 86 & 96.5 \\
\hline & TC11Cs4C1 & T. cruzi & 97 & 81 \\
\hline & TB11Cs4C1 & T. brucei & 90 & 74.4 \\
\hline & LM27Cs1C1 & L. major & 88 & 70.6 \\
\hline & LiCl1 & L. infantum & 87 & 71.6 \\
\hline & LbCl1 & L. brazilensis & 86 & 74.6 \\
\hline & G2 & L. collosoma & 84 & 78.8 \\
\hline
\end{tabular}

tol kinase gene (Tb11.47.0002) was located proximally on the sense strand (position 423851-428194).

The $\mathrm{Cl}$ gene cluster in L. major is located on both strands of chromosome 27. Two clusters of $\mathrm{Cl} 2, \mathrm{Cl}$, $\mathrm{Cl} 5$ and $\mathrm{Cl1}$ are located in the sense strand at positions 369619- 370773, preceded upstream by a phosphatidylinositol kinase (LmjF27.0890) and a hypothetical conserved protein (LmjF27.0900) and followed down- stream by another hypothetical conserved protein (LmjF27.0910). Fifty three snoRNAs are organised in the antisense strand into two arrays $(\mathrm{Cl1}, \mathrm{Cl} 3$ and $\mathrm{Cl} 6)$ and $(\mathrm{Cl1}, \mathrm{Cl} 2, \mathrm{Cl} 4$ and $\mathrm{Cl}$ ), which are intercalated and repeat five and nine times, respectively. They are located at positions 375179-383161, flanked upstream by a hypothetical conserved protein (LmjF27.0920) and the isovaleryl-CoA dehydrogenase protein (LmjF27.0930).

$\mathrm{Cl}$ gene cluster snoRNAs have not been annotated yet in the L. infantum and L. braziliensis genome projects. However, BLASTN analysis has revealed their presence on chromosome 27 from both species. Forty six snoRNAs, organised similarly to those from the antisense strand of L. major, were located in the antisense strand in L. infantum at position 310106-316427 (L. infantum GeneDB, version 3.0).

They were flanked upstream by the isovaleryl-CoA dehydrogenase protein (LinJ27_V3.0790) and a hypothetical conserved protein (LinJ27_V3.0780) and followed downstream by another hypothetical conserved protein (LinJ27_V3.0770). A phosphatidylinositol kinase gene (LinJ27_V3.0750) was located proximally on the sense strand (position 295857-301364).

In the case of L. braziliensis, there were 22 snoRNAs organised into two arrays $(\mathrm{Cl} 2, \mathrm{Cl}, \mathrm{Cl} 5$ and $\mathrm{Cl1})$ and $(\mathrm{Cl} 3, \mathrm{Cl} 6$ and a truncated $\mathrm{Cl1})$, which are intercalated and repeat four and two times, respectively. This cluster was located in the sense strand in position 380881-384367 ( $L$. braziliensis GeneDB, version 2.0) flanked upstream by a phosphatidylinositol kinase protein (LbrM27_V2.0970) and a hypothetical conserved protein (LbrM27_V2.0980) and followed downstream by another hypothetical conserved protein (LbrM27_V2.0990). An isovaleryl-CoA dehydrogenase protein (LbrM27_V2.1010) was located proximally in the antisense strand (positions 393327394559). Interestingly, two snoRNAs (Cl2 and Cl1) were found $4276 \mathrm{nt}$ downstream of the $\mathrm{Cl}$ gene cluster in position 388642-388849. It is worth noting that the copy number of each Cl-snoRNA varied within and among species, being more abundant in L. major than in the other species (Table V).

\section{DISCUSSION}

Non-protein coding RNAs (ncRNA) play critical roles in different processes affecting protein synthesis. snoRNAs (a type of ncRNA) are involved in RNA modifications leading to correct RNA folding and RNA-RNA and RNA-protein interactions (Zemann et al. 2006). It is known that snoRNAs from trypanosomatids are involved not only in rRNA processing and modifications but also in snRNA modifications thereby affecting protein synthesis and trans-splicing (Barth et al. 2005, 2008). In this study, the $\mathrm{Cl}$ gene cluster encoding several snoRNAs was characterised in $T$. rangeli and compared to those from T. cruzi, T. brucei, L. major, L. infantum, L. braziliensis and L. collosoma.

In accordance with their evolutionary origin, trypanosomatid $\mathrm{Cl}$-snoRNAs present particular features shared with those from euglenids: H/ACA snoRNAs consist of a single hairpin (Russell et al. 2004), boxes C' and D' from C/D snoRNAs can be easily distin- 
TABLE III

Intergenic regions comparison from $\mathrm{Cl}$ gene cluster from $\mathrm{C} 23 \mathrm{KP} 1(-)$ Trypanosoma rangeli strain with its homologue sequences of trypanosomes

\begin{tabular}{|c|c|c|c|c|c|c|c|c|c|c|}
\hline \multirow[b]{3}{*}{ Trypanosome } & \multicolumn{10}{|c|}{ Intergenic regions } \\
\hline & \multicolumn{2}{|c|}{$\mathrm{Cl} 2-\mathrm{Cl} 3$} & \multicolumn{2}{|c|}{$\mathrm{Cl} 3-\mathrm{Cl} 4$} & \multicolumn{2}{|c|}{$\mathrm{Cl} 4-\mathrm{Cl} 5$} & \multicolumn{2}{|c|}{$\mathrm{Cl} 5-\mathrm{Cl} 6$} & \multicolumn{2}{|c|}{$\mathrm{Cl6}-\mathrm{Cl1}$} \\
\hline & $\mathrm{bp}$ & $\%$ & bp & $\%$ & bp & $\%$ & $\mathrm{bp}$ & $\%$ & bp & $\%$ \\
\hline T. rangeli $\mathrm{C} 23$ & 61 & - & 39 & - & 30 & - & 12 & - & 71 & - \\
\hline T. rangeli $\mathrm{H} 14$ & NA & NA & 39 & 100 & 29 & 96.7 & 12 & 100 & 71 & 98.6 \\
\hline T. cruzi & 70 & 54.9 & 58 & 51.7 & 58 & 43.1 & 19 & 36.8 & 106 & 48.1 \\
\hline T. brucei & 109 & 27.5 & 70 & 22.9 & 92 & 16.3 & 50 & 14 & 37 & 25.4 \\
\hline
\end{tabular}

bp: length of the intergenic region; NA: not available; \%: percentage of identity.

TABLE IV

rRNA modifications guided by Cl-small nucleolar RNAs (snoRNAs) homologues

\begin{tabular}{|c|c|c|c|c|c|c|c|c|}
\hline \multicolumn{2}{|c|}{ Trypanosoma brucei } & \multirow{2}{*}{$\frac{\text { Leishmania major }}{\text { Site }}$} & \multicolumn{2}{|c|}{ Yeasts } & \multicolumn{2}{|c|}{ Plant } & \multicolumn{2}{|c|}{ Humans } \\
\hline snoRNA & Site & & snoRNA & Site & snoRNA & Site & snoRNA & Site \\
\hline \multirow[t]{2}{*}{ Cl1 } & $\begin{array}{c}\text { Am1326 } \\
\text { LSU 3' - PTC } \\
\text { on helix } 91\end{array}$ & Am1371 & & & AtsnoR18 & Am2924 & & \\
\hline & $\begin{array}{c}\text { Am1338 } \\
\text { LSU 3' - PTC } \\
\text { on helix } 90\end{array}$ & Am1383 & SnR71 & Am2943 & AtU29 & Am2936 & U29 & Am4493 \\
\hline \multirow[t]{2}{*}{$\mathrm{Cl} 2$} & $\begin{array}{c}\text { Um1080 } \\
\text { LSU 5' } \\
\text { on helix } 27\end{array}$ & Um847 & & & & & & \\
\hline & $\begin{array}{c}\text { Am1091 } \\
\text { LSU 5' on helix } 37\end{array}$ & Am858 & SnR39/59 & Am805 & AtU51 & Am814 & $\mathrm{U} 51 / \mathrm{U} 32 \mathrm{a}$ & Am1511 \\
\hline $\mathrm{Cl} 3$ & $\begin{array}{c}\Psi 1357 \\
\text { LSU 3' - PTC } \\
\text { on helix } 93\end{array}$ & $\Psi 1402$ & & & AtsnoR53 & Um2400 & & \\
\hline $\mathrm{Cl} 4$ & $\begin{array}{c}\text { Um611 } \\
\text { LSU 3' - PTC } \\
\text { on helix } 74\end{array}$ & Gm654 & & & & & & \\
\hline $\mathrm{Cl} 5$ & $\begin{array}{c}\Psi 1907 \\
\text { SSU on helix } 34\end{array}$ & $\Psi 1841$ & & & & & & \\
\hline & $\begin{array}{c}\Psi 61 \\
\text { SSU on helices 18-19 }\end{array}$ & & & & & & & \\
\hline $\mathrm{Cl} 6$ & $\begin{array}{c}\Psi 566 \\
\text { LSU 3' on helix } 72\end{array}$ & $\Psi 610$ & & & & & & \\
\hline
\end{tabular}

LSU3': large-subunit rRNA 3' half; LSU5': large-subunit rRNA 5' half; m: methylation; PTC: peptydil-transferase active site; SSU: small-subunit rRNA; $\Psi$ : pseudouridylation. Adapted from Liang et al. $(2005,2007)$.

guished in spite of exhibiting some variations (Russell et al. 2006) and functional isoforms allow the presence of some plasticity in the 5 ' half of transcribed regions (Liang et al. 2005, Russell et al. 2006).

Consistent with previous reports showing that snoRNAs in trypanosomatids are encoded by clusters of arrayed tandem genes, the $\mathrm{Cl}$ gene cluster repeat contains six snoRNA genes exhibiting an intercalated array of C/D and H/ACA snoRNAs.
Given the fact that the parasite requires large amounts of mature rRNA molecules, the arrangement of several alternating snoRNA genes might provide a solution to a lack of transcriptional controls in these parasites.

The $\mathrm{Cl}$ gene cluster order, size and sequence is highly conserved between the KP1(+) and KP1(-) strains from $T$. rangeli, having few mutations that affect both the transcribed and non-transcribed regions. The biological significance of this finding needs to be addressed by 
TABLE V

Copy number of Cl-small nucleolar RNAs (snoRNAs) from trypanosomatids

\section{Copy number}

(number of polymorphic or truncated sequences - identity \%)

\begin{tabular}{lcccccc}
\cline { 2 - 6 } Trypanosomatid & $\mathrm{Cl1}$ & $\mathrm{Cl} 2$ & $\mathrm{Cl} 3$ & $\mathrm{Cl} 4$ & $\mathrm{Cl5}$ & $\mathrm{Cl6}$ \\
\hline T. brucei & 5 & 5 & 5 & 6 & 6 & 5 \\
& $*$ & $*$ & $(3-98)$ & $(1-100)^{a}$ & $(1-98)$ & $*$ \\
L. major & 17 & 12 & 5 & 11 & 11 & 5 \\
& $(1-98)$ & $(4-98)$ & $*$ & $*$ & $(1-98)$ & $*$ \\
L. infantum & 13 & 10 & 3 & 9 & 9 & 4 \\
& $(3-98)$ & $*$ & $*$ & $*$ & $(3-98)$ & $(1-100)^{b}$ \\
L. braziliensis & 7 & 5 & 2 & 4 & 4 & 2 \\
& $(3-90)^{a}$ & $(1-97)$ & $*$ & $*$ & $*$ & $*$ \\
\hline
\end{tabular}

$a$ : truncated versions with the first half of the molecule; $b$ : truncated version missing the firsts $20 \mathrm{nt}$. Asterisks means absence of polymorphic or truncated-sequences.

analysing more strains. Nevertheless, it is reasonable to assume that the observed changes, especially transversion, could affect the spatial structure and function of the RNA molecule.

We observed that transcribed regions and gene order of the $\mathrm{Cl}$ gene cluster were conserved among the three species of trypanosomes studied. However, Cl-snoRNA and intergenic spacer sequence identity was higher with T. cruzi homologues than with those of T. brucei; this finding agrees with previous reports revealing a closer $T$. rangeli and $T$. cruzi phylogenetic relationship than that between T. rangeli and T. brucei (Maia da Silva et al. 2004, Diez et al. 2005, Cuervo et al. 2006).

Orthologues from $T$. cruzi phosphatidylinositol kinase (Tc00.1047053506719.10), Tb11.47.0002 and LmjF27.0890, surround the Cl-snoRNA array in T. brucei and L. major. Consequently, it is possible that the $T$. cruzi $\mathrm{Cl}$ gene cluster is located in the gene synteny region similar to what has been reported for chromosomes 11 and 27 of T. brucei and L. major, respectively (ElSayed et al. 2005).

Interestingly, $\mathrm{Cl}$ gene cluster members of leishmanias were found in different tandem arrays from those observed in trypanosomes. Taking into account the efficient expression of trypanosomatid snoRNAs, one could hypothesize that expression is influenced by extended stems formed in the extragenic flanking sequences of adjacent snoRNA molecules (Liang et al. 2007); these array order differences could have important biological consequences.

T. rangeli intergenic regions of the $\mathrm{Cl}$ gene cluster range from 12-93 nt. This range is in accordance with the minimum $10 \mathrm{nt}$ distance needed for the proper processing of each snoRNA (Xu et al. 2001, Liang et al. 2004). Indeed, $\mathrm{Cl}$ gene cluster $\mathrm{C} / \mathrm{D}$ box snoRNA expression has been described in L. collosoma (Xu et al. 2001) and $T$. brucei (Barth et al. 2008). Although there is no specific expression data from $\mathrm{Cl}-\mathrm{H} / \mathrm{ACA}$ snoRNAs, other B2 clus- ter H/ACA snoRNAs have been detected in L. collosoma by Northern blot or primer extension analysis (Xu et al. 2001, Liang et al. 2004) suggesting the expression of these snoRNAs as well. An intense signal corresponding to approximately $90 \mathrm{nt}$ has been shown in Northern blot assays in $T$. rangeli using the total $\mathrm{Cl}$ cluster as a probe, which seems to include all Cl-snoRNAs (Morales et al. 2002).

In spite of having the same copy number, $\mathrm{C} / \mathrm{D}$ snoRNAs in T. brucei have different levels of expression, with $\mathrm{Cl} 1$ showing the greatest. However, snoRNAs $\mathrm{Cl} 2$ and $\mathrm{Cl} 3$ exhibited greater target methylation as compared to Cl1 (Barth et al. 2008). These results showed that other factors aside from copy number and expression level were influencing the modification guiding process, such as the presence of secondary structure at the modification site. The Cl-snoRNA copy numbers from leishmanias differ among each snoRNA according to its array. In contrast to C/D snoRNAs Cl1 and Cl2, H/ACA snoRNAs $\mathrm{Cl} 3$ and $\mathrm{Cl} 6$ are less represented in the genome. This dosage effect might be a compensatory mechanism driven by a need for Cl-snoRNA differential expression. Likewise, in archaea and plants some Cl-snoRNAs can function as double guides, guiding two modifications at proximal $(\mathrm{Cl} 1$ and $\mathrm{Cl} 2)$ and distal $(\mathrm{Cl} 5)$ sites on the same rRNA molecule (Omer et al. 2000, Brown et al. 2003).

It was especially interesting that all $\mathrm{Cl}$-snoRNA sequences were highly conserved amongst all trypanosomatids, ranging from $61.6-88.8 \%$ identity for $\mathrm{C} / \mathrm{D}$ and from $58.4-85.7 \%$ for H/ACA snoRNAs. This finding suggests it is important for these parasites to maintain the rRNA modifications performed by $\mathrm{Cl}$-snoRNAs.

Methylation and pseudouridylation mapping carried out by Cl-snoRNA homologues in T. brucei and L. major has revealed that four modifications (Am1326, Am1338, Um611 and $\Psi 1357$ ) are located within the LSU rRNA peptidyl transferase active site. Although blocking individual rRNA modifications has not had any effect, King et al. (2003) have shown that depleting multiple modifications in the LSU reaction centre region have had synergistic, negative effects on growth.

It has been reported recently that position U611 within the LSU is $66.2 \%$ hypermethylated in bloodstream versus procyclic forms; this may help the parasite to adapt to a higher vertebrate host temperature (Barth et al. 2008).

It is of the upmost importance that homologues that carry out Am1338 (C11) and Am1091 (C12) LSU modifications have been found in yeast and even humans, implying an importance of these modifications for rRNA structure and function. On the other hand, other ClsnoRNA modifications such as Um1080 (Cl2), Um611 (Cl4), $\Psi$ 1907, $\Psi 61$ (Cl5), and $\Psi 566$ (Cl6) seem to be trypanosomatid-specific.

The finding that trypanosomatid Cl-snoRNAs share important traits such as sequence, function and specificity renders this cluster a good target candidate for medically important interventions of these parasites. For instance, a therapeutic gene expression silencing approach could be addressed. In fact, Liang et al. (2003) have reported the silencing of T. brucei TBC4 C/D snoRNA. On the other hand, species-specific differences in the nontranscribed regions of Cl-snoRNAs could be useful for 
developing PCR-based diagnostic tools. Indeed, Morales et al. (2002) have developed a PCR test specific for $T$. rangeli detection, which does not amplify the DNA of any T. cruzi groups (Pavia et al. 2007).

\section{ACKNOWLEDGEMENT}

To Dr. RS Nicholls and M Montilla, from the Parasitology Laboratory, Instituto Nacional de Salud, for kindly providing the Trypanosoma rangeli $\mathrm{H} 14$ strain.

\section{REFERENCES}

Acosta I, Romanha AJ, Cosenza H, Krettli AU 1991. Trypanosomatids isolates from Honduras: differentiation between Trypanosoma cruzi and T. rangeli. Am J Trop Med Hyg 44: 676-683.

Bachellerie JP, Michot B, Nicoloso M, Balakin A, Ni J, Fournier MJ 1995. Antisense snoRNAs: a family of nucleolar RNAs with long complementarities to rRNA. Trends Biochem Sci 20: 261-264.

Balakin AG, Smith L, Fournier MJ 1996. The RNA world of the nucleolus: two major families of small nucleolar RNAs defined by different box element with related functions. Cell 86: 823-834.

Barth S, Hury A, Liang XH, Michaeli S 2005. Elucidating the role of H/ACA-like RNAs in trans-splicing and rRNA processing via RNA interference silencing of the Trypanosoma brucei CBF5 pseudouridine synthase. J Biol Chem 280: 34558-34568.

Barth S, Shalem B, Hury A, Tkacz ID, Liang XH, Uliel S, Myslyuk I, Doniger T, Salmon-Divon M, Unger R, Michaeli S 2008. Elucidating the role of C/D snoRNA in rRNA processing and modification in Trypanosoma brucei. Eukaryot Cell 7: 86-101.

Brown JW, Echeverria M, Qu LH 2003. Plant snoRNAs: functional evolution and new modes of gene expression. Trends Plant Sci 8: 42-49.

Cuervo C, López MC, Puerta C 2006. The Trypanosoma rangeli histone $\mathrm{H} 2 \mathrm{~A}$ gene sequence serves as a differential marker for KP1 strains. Infect Genet Evol 6: 401-409.

D’Alessandro A, Saravia N 1999. Trypanosoma rangeli. In HM Gilles, Protozoal Diseases, Oxford University Press Inc, New York, p. 398-412.

Decatur WA, Fournier MJ 2003. RNA-guided nucleotide modification of ribosomal and other RNAs. J Biol Chem 278: 695-698.

Diez H, Thomas MC, Urueña CP, Santander SP, Cuervo CL, López MC, Puerta CJ 2005. Molecular characterization of the kinetoplastid membrane protein-11 genes from the parasite Trypanosoma rangeli. Parasitology 130: 643-651.

Dunbar DA, Chen AA, Wormsley S, Baserga SJ 2000a. The genes for small nucleolar RNAs in Trypanosoma brucei are organized in clusters and are transcribed as a polycistronic RNA. Nucleic Acids Res 28: 2855-2861.

Dunbar DA, Wormsley S, Lowe TM, Baserga SJ 2000b. Fibrallarin-associated box C/D small nucleolar RNAs in Trypanosoma brucei. Sequence conservation and implications for 2'-O-ribose methylation of rRNA. J Biol Chem 275: 14767-14776.

El-Sayed NM, Myler PJ, Blandin G, Berriman M, Crabtree J, Aggarwal G, Caler E, Renauld H, Worthey EA, Hertz-Fowler C, Ghedin E, Peacock C, Bartholomeu DC, Haas BJ, Tran AN, Wortman JR, Alsmark UC, Angiuoli S, Anupama A, Badger J, Bringaud F, Cadag E, Carlton JM, Cerqueira GC, Creasy T, Delcher AL, Djikeng A, Embley TM, Hauser C, Ivens AC, Kummerfeld SK, PereiraLeal JB, Nilsson D, Peterson J, Salzberg SL, Shallom J, Silva JC, Sundaram J, Westenberger S, White O, Melville SE, Donelson JE, Andersson B, Stuart KD, Hall N 2005. Comparative genomics of trypanosomatid parasitic protozoa. Science 309: 404-409.
Ganot P, Bortolin ML, Kiss T 1997. Site-specific pseudouridine formation in preribosomal RNA is guided by small nucleolar RNAs. Cell 89: 799-809.

Guhl F, Vallejo GA 2003. Trypanosoma (Herpetosoma) rangeli Tejera, 1920 - an updated review. Mem Inst Oswaldo Cruz 98: 435-442.

King TH, Liu B, McCully RR, Fournier MJ 2003. Ribosome structure and activity are altered in cells lacking snoRNPs that form pseudouridines in the peptidyl transferase center. Mol Cell Biol 11: 425-435.

Kiss-Laszlo Z, Henry Y, Kiss T 1998. Sequence and structural element of methylation guide snoRNAs essential for site-specific ribose methylation of pre-rRNA. EMBO J 17: 797-807.

Levitan A, Xu Y, Ben-Dov C, Ben-Shlomo H, Zhang Y, Michaeli S 1998. Characterization of a novel trypanosomatid small nucleolar RNA. Nucleic Acids Res 26: 1775-1783.

Liang XH, Hury A, Hoze E, Uliel S, Myslyuk I, Apatoff A, Unger R, Michaeli S 2007. Genome-wide analysis of C/D and H/ACA-like small nucleolar RNAs in Leishmania major indicates conservation among trypanosomatids in the repertoire and in their rRNA targets. Eukaryot Cell 6: 361-377.

Liang XH, Liu L, Michaeli S 2001. Identification of the first trypanosome H/ACA RNA that guides pseudouridine formation on rRNA. J Biol Chem 276: 40313-40318.

Liang XH, Liu Q, Michaeli S 2003. Small nucleolar RNA interference induced by antisense or double-stranded RNA in trypanosomatids. Proc Natl Acad Sci USA 100: 7521-7526.

Liang XH, Ochaion A, Xu YX, Liu Q, Michaeli S 2004. Small nucleolar RNA clusters in trypanosomatid Leptomonas collosoma. Genome organization, expression studies and the potential role of sequences present upstream from the first repeated cluster. $J$ Biol Chem 279: 5100-5109.

Liang XH, Uliel S, Hury A, Barth S, Doniger T, Unger R, Michaeli S 2005. A genome-wide analysis of C/D and H/ACA-like small nucleolar RNAs in Trypanosoma brucei reveals a trypanosomespecific pattern of rRNA modification. RNA 11: 619-645.

Liang XH, Xu YX, Michaeli S 2002. The spliced leader-associated RNA is a trypanosome-specific sn(o) RNA that has the potential to guide pseudouridine formation on the SL RNA. RNA 8: 237-246.

Maia da Silva FM, Noyes H, Campaner M, Junqueira AC, Coura JR, Añez N, Shaw JJ, Stevens JR, Teixeira MM 2004. Phylogeny, taxonomy and grouping of Trypanosoma rangeli isolates from man, triatomines and sylvatic mammals from widespread geographical origin based on SSU and ITS ribosomal sequences. Parasitology 129: 549-561.

Maxwell ES, Fournier MJ 1995. The small nucleolar RNAs. Annu Rev Biochem 64: 897-934.

Morales L, Romero I, Diez H, Del Portillo P, Montilla M, Nicholls S, Puerta C 2002. Characterization of a candidate Trypanosoma rangeli small nucleolar RNA gene and its application in a PCRbased parasite detection. Exp Parasitol 102: 72-80.

Ni J, Tien AL, Fournier MJ 1997. Small nucleolar RNAs direct sitespecific synthesis of pseudouridine in ribosomal RNA. Cell 89: 565-573.

Omer AD, Lowe TM, Russell AG, Ebhardt H, Eddy SR, Dennis PP 2000. Homologues of small nucleolar RNAs in Archaea. Science 288: $517-522$.

Pavia PX, Vallejo GA, Montilla M, Nicholls RS, Puerta CJ 2007. Detection of Trypanosoma cruzi and Trypanosoma rangeli infection in triatomine vectors by amplification of the histone H2A/SIRE and the sno-RNA-C11 genes. Rev Inst Med Trop São Paulo 49: 23-30. 
Pearson WR 1990. Rapid and sensitive sequence comparison with FASTP and FASTA. Meth Enzymol 183: 63-98.

Roberts TG, Sturm NR, Yee BK, Yu MC, Hartshorne T, Agabian N, Campbell DA 1998. Three small nucleolar RNAs identified from the spliced leader-associated RNA locus in kinetoplastid protozoans. Mol Cell Biol 18: 4409-4417.

Russell AG, Murray NS, Gray MW 2006. A large collection of compact Box C/D snoRNAs and their isoforms in Euglena gracilis: structural functional and evolutionary insights. J Mol Biol 357: 1548-1565.

Russell AG, Schnare MN, Gray MW 2004. Pseudouridine-guide RNAs and other Cbf5p-associated RNAs in Euglena gracilis. RNA 10: 1034-1046.

Samarsky DA, Fournier MJ, Singer RH, Bertrand E 1998. The snoRNA box C/D motif directs nucleolar targeting and also couples snoRNA synthesis and localization. The EMBO J 17: 3747-3757.

Sanger F, Nicklen S, Coulson A 1977. DNA sequencing with chain terminating inhibitors. Proc Natl Acad Sci USA 74: 5463-5546.

Stephen A, Madden T, Schaffer A, Zhang Z, Miller W, Lipman D 1997. Gapped BLAST and PSI-BLAST: a new generation of protein database search program. Nucleic Acids Res 25: 3389-3402.

Thompson JD, Higgins DG, Gibson TJ 1994. CLUSTAL W: improving the sensitivity of progressive multiple sequence alignment through sequence weighting, position-specific gap penalties and weight matrix choice. Nucleic Acids Res 22: 4673-4680.

Uliel S, Liang X, Unger R, Michaeli S 2004. Small nucleolar RNAs that guide modification in trypanosomatids: repertoire, targets, genome organization and unique functions. Int J Parasitol 34: 445-454.
Vallejo GA, Guhl F, Carranza JC, Lozano LE, Sánchez JL, Jaramillo JC, Gualtero D, Castañeda N, Silva JC, Steindel M 2002. kDNA markers define two major Trypanosoma rangeli lineages in Latin-America. Acta Trop 81: 77-82.

Vallejo GA, Guhl F, Carranza JC, Moreno J, Triana O, Grisard EC 2003. Parity between kinetoplast DNA and mini-exon gene sequences supports either clonal evolution or speciation in Trypanosoma rangeli strains isolated from Rhodnius colombiensis, $R$. pallescens and $R$. prolixus in Colombia. Infect Genet Evol 3: 39-45.

Vallejo GA, Guhl F, Carranza JC, Triana O, Pérez G, Ortiz PA, Marín DH, Villa LM, Suárez J, Sánchez IP, Pulido X, Rodríguez IB, Lozano LE, Urrea DA, Rivera FA, Cuba-Cuba C, Clavijo JA 2007. Interacción tripanosoma-vector-vertebrado y su relación con la sistemática y la epidemiología de la tripanosomiasis americana. Biomédica 27: 110-118.

Weinstein LB, Steitz JA 1999. Guided tours: from precursor snoRNA to functional snoRNP. Curr Opin Cell Biol 11: 378-384.

Xu Y, Liu L, Lopez-Estraño C, Michaeli S 2001. Expression studies on clustered trypanosomatid box C/D small nucleolar RNAs. J Biol Chem 276: 14289-14298.

Zemann A, Anja op de Bekke, Kiefmann M, Brosius J, Schmitz J 2006. Evolution of small nucleolar RNAs in nematodes. Nucleic Acids Res 34: 2676-2685.

Zuñiga C, Palau T, Penin P, Gamallo C, de Diego JA 1997. Characterization of a Trypanosoma rangeli strain of Colombian origin. Mem Inst Oswaldo Cruz 92: 523-530. 